\title{
The National Diabetes Educational Program
}

\author{
An Expert Interview with Linda Siminerio \\ University of Pittsburgh Diabetes Institute, Pittsburgh, PA, US
}

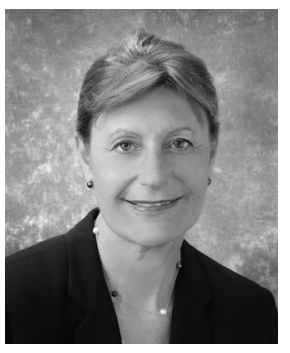

\begin{abstract}
Linda Siminerio
Linda Siminerio is Professor of Medicine and Nursing at the University of Pittsburgh and has led a career in diabetes research and education. A nationally recognized expert on self-management education and care delivery models in both pediatric and adult populations, she serves as the principal investigator on numerous studies related to diabetes prevention and treatment. Dr Siminerio served as President of Health Care and Education, American Diabetes Association and Senior Vice President, International Diabetes Federation (IDF). In these positions, she has organized and led national and international efforts on the development of programs, curricula and standards for diabetes education directed toward health professionals, patients and the community. Dr Siminerio served as organizing chair for the International Diabetes Federation (IDF) World Diabetes Congress and the IDF translation research program, BRIDGES. She is currently Chair of the National Diabetes Education Program.
\end{abstract}

DOI: https://doi.org/10.17925/USE.2018.14.1.16

\section{Keywords}

National Diabetes Education Programme (NDEP), patient education, diabetes, selfmanagement, prevention, glycemic control

Disclosure: Linda Siminerio has nothing to declare in relation to this article.

Acknowledgements: Medical writing assistance was provided by Katrina Mountfort, Touch Medical Media.

Review Process: This is an expert interview and, as such, has not undergone the journal's standard peer review process.

Authorship: All named authors meet the International Committee of Medical Journal Editors (ICMJE) criteria for authorship of this manuscript, take responsibility for the integrity of the work as a whole, and have given final approval to the version to be published.

open Access: This article is published under the Creative Commons Attribution Noncommercial License, which permits any non-commercial use, distribution, adaptation and reproduction provided the original author(s) and source are given appropriate credit. (c) The Authors 2018

Received: April 5, 2018

Published Online: May 22, 2018

Citation: US Endocrinology. 2018;14(1):16-17

Corresponding Author: Linda Siminerio, University of Pittsburgh, Falk Medical Building, Room 570, 3601 Fifth Avenue, Pittsburgh PA 15213, US. E: simineriol@upmc.edu

Support: No external funding was received in the publication of this article.
$\mathrm{T}$ he National Diabetes Education Program (NDEP) was launched in 1997. Its aims were to translate the findings of diabetes research studies into clinical and public health practice, which it has successfully achieved through engaging a range of public and private sector stakeholders; and adapting to address changing priorities in diabetes education, prevention, and care; changing demographics; and evolving communication technologies. ${ }^{1}$ The program also conducts its own population-based survey, the NDEP National Diabetes Survey (NNDS), which monitors changes in knowledge, attitudes and practices in key target audiences. ${ }^{2}$ The most recent initiative has been the Diabetes Discoveries and Practice Blog. ${ }^{3}$

In an expert interview, Linda Siminerio, recent past chair of the NDEP, from the University of Pittsburgh, Pittsburgh, PA discusses the achievements and future objective of the NDEP.

\section{Q. What are the major challenges of diabetes education?}

The major challenge is that, disappointingly, a low percentage of people in the US receive diabetes education. Much of the problem is regarding access or people not understanding the importance of education. Diabetes is a disease that requires self-management, and it is difficult when visits to a physician are often limited to four times a year, when a person living with diabetes is expected to make daily care decisions and self-manage the remainder of the year. Knowledge is the foundation for effective self-management.

\section{Q. What resources does the National Diabetes Education Program provide?}

The NDEP has partnered with many organizations across the US that represent people living with diabetes, healthcare professionals, researchers, and clinicians. These people have helped build resources available from the NDEP, including tools, videos, and educational resources such as webinars. We have also produced a blog. All are independently assessed for accuracy and relevance.

The resources address primary prevention and management of diabetes, including gestational diabetes, and have been tested within communities to ensure that they are appropriate for the target audience, as well as being culturally relevant and user friendly.

Information is available in several languages. Resources are also available to help primary care providers to promote self-management within their practice and to help motivate patients to improve self-care. 
As a federal program, the content that the NDEP develop is available at no charge to our partners for community groups that do not have the money or resources to create their own content. As long as they don't change our information, they can use it, although they can remove imagery to better reflect the community they represent. This is a valuable service for people working within communities who want access to a trusted source of information.

\section{Q. Over the last 20 years, what do you consider the greatest achievements of the NDEP?}

The people who represent the NDEP recognize the need to adapt with the times. In the early days, care was provider-directed and education delivery's main focus was providing knowledge. However, people in the diabetes community gradually realized that just providing knowledge was not necessarily changing behavior, and we needed to provide people living with diabetes and healthcare providers with the tools and materials to enable behavioral change. One of our greatest accomplishments is a unique step within the NDEP compendium called Diabetes HealthSense. For people who have been trained in a traditional model, it is useful to have the resources to facilitate behavioral change strategies.

In addition, the NDEP has engaged stakeholders from its inception; this continues to be a significant achievement.

An important development during the evolution of the NDEP is the inclusion of primary prevention resources. At the beginning, the most important message to disseminate was that of good glycemic control to prevent the complications of diabetes. Since evidence has accumulated to support the prevention and delay of type 2 diabetes, the NDEP has responded with robust materials and opportunities for primary prevention.

\section{Q. Could you tell us a little about the National Diabetes Survey and how it is used for strategic planning?}

The National Diabetes Survey (NNDS) was started by the NDEP in 2006 to help understand the attitudes and behaviors of US adults regarding awareness, understanding, prevention and management of diabetes. The survey is performed every 2-3 years, and we have learned that awareness of diabetes is high, but this is not necessarily translating into action. For example, we found that there is low awareness of the fact that 2 out of 3 people with diabetes will die from heart attack or stroke. There is also low awareness of certain risks for developing type 2 diabetes, such as family health history. This is useful for our program planning purposes as it helps us formulate the messages we want to communicate. We have adapted to new technologies over the years; online panel surveys are increasingly used. The sample size for the latest NNDS was over 2,500 people and every survey has included a target oversample for Hispanic and non-Hispanic black people. The NNDS is published to help inform and guide other healthcare professionals. ${ }^{2}$

\section{Q. What are the aims of the NDEP for 2018 ?}

We need to continue to deliver information in a way that all people in the US will respond to. Mobile phones are increasingly used for surveys. We need to get information out about community-based programs such as the National Diabetes Prevention Program. We also need to continue to promote behavior change and share insights about tools and technologies to improve diabetes self-management. One example is the annual symposium at the American Diabetes Association meeting. This year's symposium will feature speakers talking about the benefits, potential challenges, and limitations of using digital tools and technologies in diabetes care and diabetes selfmanagement education.

The way we deliver content is constantly evolving and changing; we know that a lot of visitors access our website using mobile phones, so this affects how our content is presented. We've moved to a "bite snack meal" approach, so users can get a general sense of the content but can click to find out more, download pdfs, etc. The growth of online content also means that, as science changes, we can add that information onto the website immediately, rather than waiting for the next print publication. We continue to have webinars and presentations, but when day-to-day developments change quickly, there is a need to disseminate information. The blog launched in November 2017 and aims to bring healthcare professionals together to talk about issues in diabetes care and management, and share challenges, success stories, practical pearls, exchange ideas, and have conversations. We post content once a week, which allows us to bring people forward in the community who might not otherwise have a chance; not everyone is able to attend annual meetings or conferences. $\square$

1. Siminerio LM, Albright A, Fradkin J, et al. The National Diabetes Education Program at 20 Years: Lessons Learned and Plans for the Future. Diabetes Care. 2018;41:209-18.

2. Griffey S, Piccinino L, Gallivan J, et al. Applying national survey results for strategic planning and program improvement: the National Diabetes Education Program. Eval Program Plann. 2015;48:83-9.

3. National Diabetes Education Program. Diabetes Discoveries \& Practice Blog. Available at: www.niddk.nih.gov/health-information/professionals/diabetes-discoveries-practice (accessed April 9, 2018). 